\title{
Localized Wave Generation With a Standard Underwater Array
}

\author{
D. Kent Lewis \\ David H. Chambers \\ Christopher S. Mullin \\ Richard W. Ziolkowski
}

This paper was prepared for submittal to the 16th International Congress on Acoustics and 135th Meeting Acoustical Society of America

Seattle, Washington

June 20-26, 1998

February 17, 1998

This is a preprint of a paper intended for publication in a journal or proceedings. Since changes may be made before publication, this preprint is made available with the understanding that it will not be cited or reproduced without the permission of the author. 


\section{DISCLAIMER}

This document was prepared as an account of work sponsored by an agency of the United States Government. Neither the United States Government nor the University of California nor any of their employees, makes any warranty, express or implied, or assumes any legal liability or responsibility for the accuracy, completeness, or usefulness of any information, apparatus, product, or process

disclosed, or represents that its use would not infringe privately owned rights. Reference herein to any specific commercial product, process, or service by trade name, trademark, manufacturer, or otherwise, does not necessarily constitute or imply its endorsement, recommendation, or favoring by the United States Government or the University of California. The views and opinions of authors expressed herein do not necessarily state or reflect those of the United States Government or the University of California, and shall not be used for advertising or product endorsement purposes. 


\title{
Localized wave generation with a standard underwater array
}

\author{
D. Kent Lewis, David H. Chambers. Christopher S. Mullin and ${ }^{\ddagger}$ Richard W. Ziolkowski
}

Lawrence Livermore National Laboratory, 7000 East Avenue, Mail Stop L - 372, Livermore, CA 94550 USA

${ }^{*}$ University of Arizona, Dept. of Electrical and Computer Engineering, Tucson, AR 85721, USA

\begin{abstract}
Recent work at the Navy Underwater Weapons Center Keyport test facility showed that existing Navy field equipment could generate Localized Waves. Results of angular scans show a narrowed beam pattern and lowered side lobes relative to standard beams. Results of axial range scans show evidence or an extended near field. Frequency analysis shows that the main beam is a decade wide while the surviving grating lobes are narrow band width, high frequency.
\end{abstract}

\section{INTRODUCTION}

Previous tests of the Localized Wave pulse generation were carried out with optimized laboratory equipment at Lawrence Livermore National Laboratory. In all of these tests the Localized Wave had outperformed other comparison beams. This left as a question whether or not the beam could be generated using existing underwater equipment.

The tests presented in this work were performed using a standard test facility and standard measurement devices of the NUWC Keyport facility. In addition to the Modified Pulse Spectrum, reported on in previous work, we tested the Superposed Gaussian pulse beam.

\section{TEST SETUP}

Tests were conducted in the NUWC Keyport Acoustic Test Facility, a cylindrical tank 30 feet in diameter and 30 feet deep. The array was mounted on a movable strut which could be moved in a level plane from -120 degrees to 120 degrees relative to the tank diameter. The receiver, a calibrated F-50 hydrophone, was mounted on a movable platform orientated along the tank diameter. The receiver platform could be moved via an air bearing which allowed hand positioning of the receiver.

The array was an AdCap field array driven by operational amplifiers mounted in the underwater head assembly. The elements were driven with voltages of $+/-10$ volts maximum. The array was driven with pre-compensated signals to generate sound covering a decade of usable bandwidth. The elements were grouped by radius from the center and excited by signals designed specifically for each radius.

Current and voltage measurements were made at the head mounted amplifier output as well as at the amplifier at the dry end of the communication cable. The impedance and admittance of the water loaded array elements were calculated from these measurements.

\section{SIGNAL PRECOMPENSATION}

The array drive signals were precompensated to correct for irregularities in the array element response over the frequency band width of interest. This pre-compensated employed inverse filtering techniques. A series of broad band width Gaussian pulses was launched to determine the response limits of the array / detector combination. A pulse matching these limits was then designed and launched to measure the system response for the frequency band to be used, and the inverse of that response convolved through the source signals to create pre-compensated initial signals. 


\section{MEASUREMENT AND CONTROL SYSTEM}

Several different beams were tested in these experiments, the Modified Pulse Spectrum beam, the Superposed Gaussian beam, and several different frequency tone bursts. The range of usable frequency response was found to be 5 to $65 \mathrm{kHz}$, limited by the F-50 response, and tone bursts were tested from 18 to $50 \mathrm{kHz}$.

The head position was controlled by our control computer interfaced to the mounting arm's computer via GPIB communication. Tests were made to assure that the positioning was repeatable, and accuracy to within a tenth of a degree was found to be stable.

Source signals were generated and compensated on a workstation and downloaded to the control computer. These signals were then uploaded to an arbitrary pulse generator.

The signal generator output the signal into a bank of amplifiers which transmitted those signals through a 30 foot cable to the head mounted amplifiers. The output of the head amps drove the array elements. The resultant fields were detected by the F-50, and amplified by a calibrated amplifier. The output of the system was digitized and averaged by a sampling oscilloscope and returned to the control computer.

Once the inverse filter for the system had been determined, that filter was used for all signals for the rest of the experiment, there was no feedback control involved.

\section{TEST PROCEDURE}

An angular scan over 180 degrees was made for each signal used, and data was acquired at 1.5 degree intervals. Each signal was the result of averaging 100 signals in the oscilloscope. In all cases the amplifier settings were kept constant. The distance from the center of the array to the receiver was also constant at 15 feet, as per standard testing procedures. Positioning and data acquisition were controlled by the control computer.

A distance scan was made by launching each of the test signals at the same relative positioning of the array and receiver. The receiver was then moved, and the procedure repeated. The array was pointed along the tank diameter in all the distance tests. The range covered from slightly more than a meter, the closest possible spacing, to 5 meters, the farthest spacing.

\section{TEST RESULTS AND CONCLUSIONS}

Angular beam results showed a better beam pattern for the Localized Wave pulses than for the tone bursts overall. The higher frequency tones exhibited high side lobe characteristics as expected. The Localized Wave beams showed lowered but still persisting side lobes where grating lobes were expected.

Frequency bandwidth results showed that the Localized Wave pre-compensated signals gave a smooth and usable bandwidth of over a decade, from 5 to $65 \mathrm{kHz}$. The energy in the persisting side lobes was in a very narrow band in the high frequency range.

The range results showed evidence of an extended near field transition distance. The efficiency was not as high as hoped due to the significant power needed to control the various resonances of the array assembly.

Tests were performed in a standard NUWC test facility using standard arrays and equipment. Several different Localized Wave beams were generated, and evidence of near field distance extension was observed.

\section{ACKNOWLEDGMENTS}

This work was performed under the auspices of the United States Dept. of Energy by the Lawrence Livermore National Laboratory under Contract W-7405-Eng-48. 


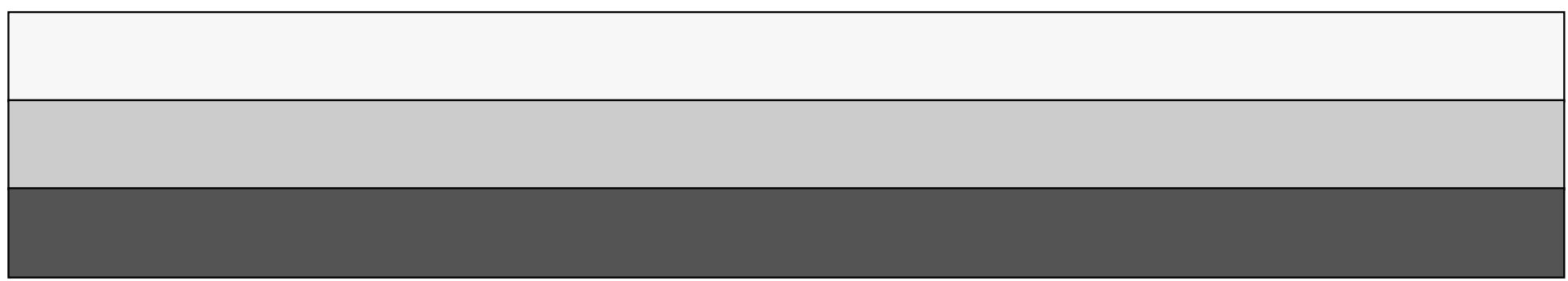

